\title{
Blanchfield Army Community Hospital Polypharmacy Clinic
}

\author{
Kevin J. Ridderhoff, RPh, MHA; Jessica R. Hull, PharmD, BCPS; and Sheila K. Sandberg, PharmD, BCPS
}

\section{SUMMARY}

The increased use of central nervous system depressants (CNSD) and psychotropics are one of the many factors that contribute to suicidal behavior in soldiers. U.S. Army policy requires medication screening for any soldier prescribed 4 or more medications when at least 1 of the medications is a CNSD or psychotropic. Constant deployments challenged health care provider ability to comply with required screenings, and senior leaders sought proactive intervention to reduce medication risks upon return of the 101st Airborne Division (Air Assault) from deployment in 2011.

A pharmacy-led team established the Polypharmacy Clinic (PC) at Blanchfield Army Community Hospital. Of the 3,999 soldiers assigned, 540 $(13.5 \%)$ met the initial screening criteria. Success of the pilot program led to the mandatory screening of all other Fort Campbell, Kentucky, brigades. During the first 12 months, 895 soldiers were seen by a clinical pharmacist, and 1,574 interventions were documented. Significant interventions included medication added (121), medication changed (258), medication stopped (164), lab monitoring recommended (172), adverse reaction mitigated (41), therapeutic duplication prevented (61), and drug-drug interaction identified (93). Additionally, 55 soldiers were recommended for temporary duty profiles based on their adverse drug effects. Ten soldiers were recommended for enhanced controlled substance monitoring.

Placing soldiers on clinically appropriate medications and removing potentially harmful medications from their possession are examples of how the PC positively impacted the Commanding General's ability to deploy a fully medically ready force. Soldiers consistently remarked favorably on the thorough medication counseling provided at their PC appointments. Innovative notes within the electronic health record summarized relevant findings regarding soldiers' medications, which allowed providers to quickly pinpoint and adjust medication regimens. With each identified high-risk soldier, we decreased the potential for postdeployment medication issues. Additionally, the PC generated over $\$ 70,000$ in relative value units for the hospital.

J Manag Care Pharm. 2015;21(1):8-11

Copyright $\odot 2015$, Academy of Managed Care Pharmacy. All rights reserved.

B lanchfield Army Community Hospital (BACH) is a Level III trauma facility at Fort Campbell, Kentucky. The military installation is home to the 101st Airborne Division (Air Assault), one of the U.S. Army's premier light infantry units. Over 1,500 soldiers, civilians, and contractors make up the staff of BACH, which delivers health care to 120,000 soldiers, family members, and eligible retirees. Many soldiers assigned to Fort Campbell have deployed multiple times, and the entire division has served 4 combat tours since September 11, 2001. The constant demands of training for and serving in war create challenges for continual medical surveillance. Garrison health care, or health care delivered in fixed military treatment facilities such as BACH, is routinely well documented in the Department of Defense electronic health record (EHR) system Armed Forces Health Longitudinal Technology Application (AHLTA). However, health care delivered in mobile or deployed environments is not easily documented as part of the comprehensive EHR. The irregular connectivity between deployed and garrison EHRs leaves gaps in prescription drug visibility. Primary care managers (PCM) are also faced with conducting complex tasks during 20-minute appointments, limiting time available for medication reconciliation.

In 2011, over 28,000 soldiers returned from Afghanistan to Fort Campbell with approximately 18 months to reset equipment and train for future deployments. This reset cycle was slightly longer than previous years and presented an opportunity to initiate preventive medical screening. ${ }^{.}$Hospital leadership, in close concert with division medical leaders, recognized the potential to decrease medication-related problems in the garrison following the deployment. The problem was how to screen the 4 returning infantry brigade combat teams (BCT) and other combat support units for polypharmacy and conduct individual medication reconciliation during the reset cycle before postdeployment medication issues surfaced. U.S. Army Medical Command policy requires medication screening by a clinical pharmacist for any soldier prescribed 4 or more medications when at least 1 of the medications is a central nervous system depressant (CNSD) or psychotropic. ${ }^{2}$ The increased use of CNSDs and psychotropics is one of the many factors contributing to suicidal behavior in soldiers. ${ }^{2,3}$ Although $\mathrm{BACH}$ providers received polypharmacy training in 2010, less than 10 referrals to a clinical pharmacist were requested in the following 9 months.

\section{Leadership}

The Director of Pharmacy (DOP) was tasked with conducting a feasibility analysis for establishing a polypharmacy clinic. The senior medical officer (Division Surgeon), ultimately responsible for deploying a fully medically ready force, also desired to decrease the prescription burden on future deployments. ${ }^{4}$ Inquiries to other army military treatment facilities revealed that the prevailing model relied upon consults; a proactive polypharmacy clinic (PC) had not yet been established.

Led by the DOP, the mission analysis team also included a clinical pharmacist, the Chief Medical Officer, the Chief Operating Officer, and the Hospital Commander (CEO). Vital planning factors included estimating the number of soldiers with polypharmacy, capacity to screen for and complete 
medication reviews, and participation of line unit medical providers and leadership. The initial estimate was that $25 \%$, or about 1,000 soldiers, of each BCT would meet polypharmacy criteria. Clinical pharmacy appointments were projected at 20 minutes, and the completion time for each BCT projected at 15 weeks. Participation with line unit leadership was pivotal. Without strong endorsement by the line unit and communication between the clinical pharmacist and line medical providers, the impact of reducing medication risks could potentially be lessened.

A business case analysis to accomplish the pharmacy-initiated polypharmacy reviews requested $\$ 185,000$ for a clinical pharmacist and pharmacy technician and $\$ 5,000$ for space and equipment. The clinical pharmacist was projected to earn $\$ 113,000$ in relative value units (RVUs), leaving $\$ 72,000$ in atrisk additional manpower expense. ${ }^{5}$ The Hospital Commander approved the analysis in August 2011, requesting the screening of the entire division in order to mitigate risks during the transitional period between deployments.

\section{Planning and Implementation}

The PC set up location in the LaPointe Health Clinic; the same facility where soldiers received the majority of their health care. Changes to the EHR were required to allow clinical documentation from the PC. The new configuration enabled the receipt of consults, electronic communication with providers, and RVU generation. A clinical pharmacist and a pharmacy technician were recruited to staff the PC.

The DOP selected one of the infantry BCTs as the pilot group to validate the PC model. The selection was influenced by the potential for deployment orders. Identifying the target population required assistance from the line medical providers. A personnel roster, along with therapeutic class codes for psychotropics and CNSDs, was sent to the Defense Health Agency Pharmacy Operations Division (formerly known as the Department of Defense Pharmacoeconomic Center) for screening. ${ }^{6}$ Of the 3,999 soldiers assigned to the BCT, 540 (13.5\%) met the initial screening criteria ( $>3$ medications, with 1 CNSD or psychotropic within the previous 90 days). The first polypharmacy soldier was seen in the PC in October 2011.

During the pilot BCT screening process, several key elements were identified. The appointment time was underestimated at 20 minutes. Executing medication reconciliation, along with counseling, documentation, and communication with other providers took more than 60 minutes on average. Another element was differentiation between acute and nonacute polypharmacy. While the clinical pharmacist screening revealed 540 of 3,999 soldiers (13.5\%) had 4 or more medications within the previous 90 days, some of the screened soldiers were not on chronic medications. Additional profile reviews were needed to identify and eliminate acute polypharmacy patients (e.g., those preparing for LASIK surgery).
Communication was also a key determinant. By personally meeting with the brigade nurse and other key medical providers, the clinical pharmacy team kept the line unit engaged. Requiring soldiers to bring their medications to their appointments was another element to consider. During the interview, the clinical pharmacist regularly identified discrepancies in the EHR, along with duplications, interactions, and expired medications. Having the medications present aided in more complete documentation in the medication profile.

The clinical pharmacist utilized an innovative communication tool within the EHR. After documenting an extensive polypharmacy encounter, the clinical pharmacist created an electronic tasking to the PCM. This tasking summarized the seminal clinical recommendations for the PCM and was the important and desired link to keep the line unit medical providers informed. The tasking allowed the pharmacist to track provider response. The use of time-based Current Procedural Terminology codes for medication therapy management in the documentation process allowed the pharmacy to capture RVUs, expense factors that determine hospital reimbursement and help defray some of the manpower expense.

Another pharmacy-provider communication tool was the electronic profile (eProfile). The eProfile records limitations or restrictions on soldier duties. ${ }^{7}$ The clinical pharmacist created a template for use when medication side effects could potentially affect safety. The eProfile was electronically sent to the medical provider for signature, thus keeping the unit abreast of medical readiness. Ultimately, the goals of keeping the line unit medical providers involved and tailoring individual soldier treatment plans were met.

The pilot BCT screening was completed in 11 weeks. The clinical pharmacy team, after adjusting for nonacute polypharmacy, documented over 270 interventions during 218 appointments. Discontinuing medications, changing medications, monitoring lab values, and adding medications were the most frequent interventions. Thorough interviews and record reviews routinely demonstrated opportunities to decrease medication risks. For example, several interventions involved serotonin modulators with increased risk of serotonin syndrome, highlighting the need to educate providers on certain drug-drug interactions.

Because of documented improvements in patient outcomes, the clinical pharmacy team screened the remaining 24,000 soldiers in the garrison. Soldiers continually entering and leaving a combat unit created concern about dated polypharmacy information. Obtaining the personnel roster, executing the preliminary screening, removing the acute polypharmacy users, and conducting clinical interviews took an average of 15 weeks. The challenge became identifying newly arrived polypharmacy soldiers. The polypharmacy team began coordinating with the unit that in-processes Fort Campbell personnel. Weekly personnel rosters were screened for polypharmacy criteria for 
new soldiers. This information was provided to the gaining line unit medical staff, arming them with valuable insight about their new soldiers and associated polypharmacy risk. Finally, the clinical pharmacy team became concerned about provider burnout. The charge to care for a primarily young population, many having served their country in combat, coupled with the arduous task of screening the entire division before the next deployment was significant. The DOP instituted an administrative day to ensure that provider communication, administrative tasks, data capture, and emotional health were addressed.

\section{Measurable Outcomes and Impact}

The initial screening of all 27,999 soldiers in the garrison and polypharmacy clinic appointments for 895 at-risk soldiers were completed in December 2012. Placing soldiers on clinically appropriate medications and removing potentially harmful medications from their possession are examples of how the PC positively impacted the Commanding General's ability to deploy a fully medically ready force. Overall polypharmacy use ranged from $2.2 \%$ to $7.6 \%$ for each brigade, far lower than initially projected. The 4 BCTs and 2 combat aviation brigades ranged from $2.2 \%-4.2 \%$, and $7.6 \%$ and $5.9 \%$ of 2 combat support units met polypharmacy criteria, possibly reflecting the overall medical composition of these units. Of the 895 appointments, 81 were initiated through provider consults. The clinical pharmacist and technician documented 1,574 interventions in 12 months. Significant interventions included medication added (121), medication changed (258), medication stopped (164), lab monitoring recommended (172), adverse reaction mitigated (41), therapeutic duplication prevented (61), and drug-drug interaction identified (93). Additionally, 55 eProfiles were recorded, and 10 soldiers were recommended for sole provider contracts, an agreement for enhanced monitoring of controlled substances. Medications considered deploymentlimiting numbered 73 . The mean soldier age was 31.5 years and ranged from 20 to 62 years. Of the soldiers seen, 730 (81.6\%) were male (see Table 1). The clinical pharmacy team intervened with 1 soldier who had lost the desire to live. Additionally, the PC generated $\$ 70,993$ in RVUs for the hospital. While this was less than projected, the Hospital Commander reiterated support for comprehensive medication review and EHR documentation.

\section{Innovation and Generalizability}

This proactive model has been applied to other applications. During the course of this project, hospital leaders grappled with the challenges of varenicline (Chantix), buprenorphine and naloxone (Suboxone), and stimulant use, as well as diagnoses of bipolar disorders. Each challenge was met by using the same formula of identifying prescriptions from all military treatment facility, retail, and mail order pharmacy points of service; engaging the line unit medical providers; and making clinical recommendations to the Medical Staff Executive

\section{TABLE 1 Polypharmacy Clinic Intervention} Outcomes

\begin{tabular}{l|rc}
\hline Demographic characteristics & \multicolumn{2}{|c}{$\begin{array}{c}\text { Number } \\
\text { N (n/1,000 appts) }\end{array}$} \\
\hline Total (\% male) & 895 & $(81.6)$ \\
\hline Age, years-mean (range) & 31.5 & $(20-62)$ \\
\hline Consults to service, $\mathrm{n}(\%)$ & 81 & $(9.1)$ \\
\hline Intervention & \multicolumn{1}{c}{} \\
\hline Adverse reaction mitigated & 132 & $(118.1)$ \\
\hline Dose changed & 93 & $(83.2)$ \\
\hline Drug/drug interaction & 10 & $(9.0)$ \\
\hline Enrolled in sole provider program & 55 & $(49.2)$ \\
\hline eProfile generated & 30 & $(26.9)$ \\
\hline Excess controlled medication destroyed & 63 & $(56.4)$ \\
\hline Excess noncontrolled medication destroyed & 172 & $(153.9)$ \\
\hline Lab monitoring recommended & 121 & $(108.3)$ \\
\hline Medication added & 258 & $(230.9)$ \\
\hline Medication changed & 164 & $(146.8)$ \\
\hline Medication stopped & 60 & $(53.7)$ \\
\hline Therapeutic duplication prevented & 73 & $(65.3)$ \\
\hline Nondeployable medication identified & &
\end{tabular}

Committee. Several policy changes were made to increase the safety and surveillance of specific drug classes.

In 2013, Fort Campbell Department of Pharmacy was selected by the Office of the Surgeon General as a pilot site to further advance safe medication use. This initiative combines emergency room utilization involving an opioid medication; multiple medication usage in addition to an opioid; and utilization of 4 or more opioids, antidepressant medications, anxiolytics, sleep medications, anticonvulsants, stimulants, or antipsychotics in combination. The current polypharmacy policy incorporates these criteria into a revised polypharmacy definition, which mandates clinical reviews with specific time and drug class targets. ${ }^{8}$ The goal is to engage all health care providers in proactive intervention to improve soldier medical readiness.

Other opportunities include expanding polypharmacy screening to family members and conducting ongoing monthly reviews for all Fort Campbell units. One community-based medical home with 7,848 enrolled Fort Campbell dependents revealed that $613(7.8 \%)$ dependents met polypharmacy criteria. Additional clinical pharmacists are necessary to address medication concerns in this population. As units continue to deploy and federal government fiscal constraints are applied, regular line unit screening will not be without effort. These challenges are indeed worthwhile to reconcile profiles and prepare a fully medically ready force for the soldiers of the 101st Airborne Division (Air Assault). The single potential suicide intervention, along with reduced medication-related incidents during the reset period, demonstrates the power that a committed and communicative health care team can wield toward safer medication use. 


\section{Authors}

KEVIN J. RIDDERHOFF, RPh, MHA, is Deputy Director, Formulary Management Branch, Pharmacy Operations Division, Defense Health Agency, Falls Church, Virginia; JESSICA R. HULL, PharmD, BCPS, is Clinical Pharmacy Director, Womack Army Medical Center, Fort Bragg, North Carolina; and SHEILA K. SANDBERG, PharmD, BCPS, is a Clinical Pharmacist in Nashville, Tennessee.

AUTHOR CORRESPONDENCE: Kevin J. Ridderhoff, RPh, MHA, Pharmacy Operations Division, Defense Health Agency, 7700 Arlington Blvd., Ste. 501, Falls Church, VA 22042. Tel.: 703.681.5174; E-mail: kevin.ridderhoff@dha.mil.

\section{DISCLOSURES}

The authors have no conflicts of interest to disclose. The views and opinions of the authors expressed herein do not necessarily state or reflect those of the U.S. government.

Ridderhoff, Hull, and Sandberg designed the study. Sandberg was primarily responsible for data collection, assisted by Hull and Ridderhoff, and Hull interpreted the data, assisted by Sandberg and Ridderhoff. The manuscript was written and revised by Ridderhoff, Hull, and Sandberg.

\section{REFERENCES}

1. Scurfield RM, Platoni KT, eds. War Trauma and Its Wake, Expanding the Circle of Healing. New York: Routledge; 2013.
2. Office of the Surgeon General (OTSG)/The U.S. Army Medical Command (MEDCOM). Policy Memo 10-076: Guidance for enhancing soldier safety and reducing risk via the prevention and management of polypharmacy involving psychotropic medications and central nervous system depressants. November 2010. Policy superseded by Policy Memo 13-032. May 2013. [see Reference 8].

3. Kinn JT, Luxton DD, Reger MA, Gahm GA, Skopp NA, Bush NE. Department of Defense suicide event report. Calendar year 2010 annual report. National Center for Telehealth \& Technology. 2011. Available at: http://t2health.dcoe.mil/sites/default/files/dodser/DoDSER_2010_Annual_ Report.pdf. Accessed November 18, 2014.

4. U.S. Army. 2010 U.S. Army posture statement. Medical and dental readiness. Available at: https://secureweb2.hqda.pentagon.mil/vdas_armyposturestatement/2010/information_papers/Medical_and_Dental_Readiness.asp. Accessed November 18, 2014.

5. Dummit LA. Relative value units (RVUs). National Health Policy Forum. February 12, 2009. Available at: http://www.nhpf.org/library/the-basics/ Basics_RVUs_02-12-09.pdf. Accessed November 18, 2014.

6. Trice S, Devine J, Mistry H, Moore E, Linton A. Formulary management in the Department of Defense. J Manag Care Pharm. 2009;15(2):133-46. Available at: http://www.amcp.org/data/jmcp/133-146.pdf.

7. U.S. Army Medical Command. Soldier medical readiness campaign plan 2011-2016. Version 1.2. May 2011. Available at: https://www.yumpu.com/ en/document/view/11717380/us-army-medical-command-soldier-medicalreadiness-campaign. Accessed November 18, 2014.

8. Office of the Surgeon General (OTSG)/The U.S. Army Medical Command (MEDCOM). Policy Memo 13-032. Guidance for managing polypharmacy and preventing medication overdose in soldiers prescribed psychotropic medications and central nervous system depressants. May 21, 2013. Available at: http://pec.ha.osd.mil/PMART/Polypharmacy\%20POLICY\%20 13-032\%20(2).pdf. Accessed November 18, 2014. 